\title{
A chitin-binding domain in a marine bacterial chitinase and other microbial chitinases: implications for the ecology and evolution of 1,4- $\beta$-glycanases
}

\author{
Amy L. Svitil and David L. Kirchman \\ Author for correspondence: David L. Kirchman. Tel: +1 302645 4375. Fax: +1 3026454028. \\ e-mail: KIRCHMAN@UDEL.EDU
}

College of Marine Studies, University of Delaware, Lewes, DE 19958, USA

\begin{abstract}
To examine the ecology and evolution of microbial chitinases, especially the chitin-binding domain, one of the chitinase genes (chiA) from the marine bacterium Vibrio harveyi was analysed. The deduced amino acid sequence of ChiA is not very similar overall to other proteins, except for two regions, the putative catalytic and chitin-binding domains. Among all bacterial chitinases sequenced to date, there is no relationship between percentage similarity of catalytic domains and chitin-binding domains in pairwise comparisons, suggesting that these two domains have evolved separately. The chitinbinding domain appears to be evolutionarily conserved among many bacterial chitinases and is also somewhat similar to cellulose-binding domains found in microbial cellulases and xylanases. To investigate the role of the chitin-binding domain, clones producing versions of ChiA with or without this domain were examined. One version with the domain (ChiA1) bound to and hydrolysed chitin, whereas a truncated ChiA without the putative chitin-binding domain (ChiA2) did not bind to chitin, but it could hydrolyse chitin, although not as well. ChiA1 diffused more slowly in agarose containing colloidal chitin than ChiA2, but diffusion of the two proteins in agarose without colloidal chitin was similar. These results indicate that the chitin-binding domain helps determine the movement of chitinase along $\mathbf{N}$-acetylglucosamine strands and within environments containing chitin.
\end{abstract}

Keywords: Vibrio barveyi, chitinase, chitin-binding domain, cellulose-binding domain

\section{INTRODUCTION}

Cellulose and chitin, the first and second most abundant biopolymers in nature, are composed of $1,4-\beta$-linked pyranose units whose glycosidic bonds are hydrolysed by cellulases and chitinases, respectively. These enzymes consist of discrete domains, which can be arranged in different orders in different proteins (for reviews, see Béguin, 1990; Gilkes et al., 1991; Warren, 1996). Perhaps the two most important domains are those involved in catalysing the hydrolysis of the glycosidic bonds (the catalytic domain) and in mediating the binding of the

Abbreviation: MUF-diNAG, 4-methylumbelliferyl $\beta$-D-N, $N^{\prime}$-diacetylchitobioside.

The GenBank accession number for the sequence reported in this paper is U81496. enzyme to the substrate (the carbohydrate-binding domain). Cellulose-binding domains are not essential for catalytic activity, but they do control the specific activities of the enzyme on different forms of cellulose (Coutinho et al., 1993). Less is known about chitinbinding domains, especially in bacterial proteins (Graham \& Sticklen, 1994; Warren, 1996).

Chitin-binding domains in plant proteins have been examined extensively (Graham \& Sticklen, 1994). Certain positions within the chitin-binding domain, notably the eight cysteines, are highly conserved among plant chitinases (Graham \& Sticklen, 1994). In addition to chitinases, plants have chitin-binding proteins (lectins) without chitinase activity, which also contain the cysteine-rich chitin-binding domain (Graham \& Sticklen, 1994). In contrast, the chitin-binding domain of chitinase A1 from Bacillus circulans WL-12 contains 
only one cysteine and is not similar to that of plants (Watanabe et al., 1994). Recently, Morimoto et al. (1997) found several other similar residues among chitinbinding domains from bacterial chitinases and observed that removal of the binding domain decreased hydrolysis of unprocessed chitin by a chitinase from Clostridium paraputrificum. The role of the chitin-binding domain in hydrolysing chitin by other chitinases is not clear.

In addition to the chitin-binding domain, other regions of bacterial chitinases are not very similar to plant chitinases nor to each other (Watanabe et al., 1993). Watanabe et al. (1993) identified only four amino acids in the catalytic domain that are conserved between bacterial and plant class III chitinases. The diversity in chitinases is not unexpected because the structure of chitin is very diverse due to variation in arrangement of strands, degree of deacetylation and cross-linking to other structural components (Gooday, 1990). However, recently Chernin et al. (1997) did find several similar regions among six bacterial chitinases and suggested that enzymes from closely related bacteria are more similar than enzymes from distantly related bacteria. In contrast, catalytic domains of cellulases do not appear to follow phylogeny, although cellulose-binding domains in cellulases from a single bacterium can be quite similar (Gilkes et al., 1991).

To gain a better understanding of bacterial chitinases and especially the chitin-binding domain, we examined a chitinase (ChiA) from the marine bacterium Vibrio harveyi. Chitin is potentially an important nutrient source for marine bacteria since it is produced by many marine organisms, including zooplankton and several phytoplankton species (Gooday, 1990). Previous work on $V$. harveyi has identified six separate chitinase genes (Svitil et al., 1997), and two genes encoding chitin degradation enzymes have been at least partially sequenced (Jannatipour et al., 1987; Soto-Gil, 1988). One of the partially sequenced genes encodes a chitinase, ChiA (Soto-Gil, 1988). Here we analysed the complete sequence of $c h i A$ and identified a chitin-binding domain specific to bacteria. The binding domain appears to help determine the movement of the enzyme along chitin strands and in its environment.

\section{METHODS}

Strains and vectors. $V$, harveyi strain $\mathrm{BB} 7$ was grown in LM ( $1 \%$ tryptone, $0.5 \%$ yeast extract, $2 \% \mathrm{NaCl}$ ). Escherichia coli strains XL-1 Blue MRF' and SOLR were grown in LB (1\% tryptone, $0.5 \%$ yeast extract, $0.5 \% \mathrm{NaCl}$ ), unless otherwise noted. The phagemid pBluescript II KS(-) (Stratagene) was used for subcloning.

Genomic library construction and screening. Previous work by Soto-Gil (1988) had partially sequenced what was identified as the gene encoding the main chitinase in $V$. harveyi BB7, $c h i A$. To complete the sequencing and analysis of this chitinase we constructed and screened two V. harveyi genomic libraries. The first library was constructed in pBluescript II $\mathrm{KS}(-)$, while the second was a plaque library prepared in $\lambda$ ZAP II (both vectors from Stratagene) (Svitil et al., 1997).
The libraries were screened using a digoxigenin-labelled $c h i A 1$ probe, which corresponds to the portion of $c h i A$ sequenced by Soto-Gil (1988). Positive clones or plaques were detected by colour (alkaline phosphatase) using the Genus kit (Boehringer Mannheim). After isolating positive plaques, the plasmid [pBluescript II SK $(-)$ containing the insert] was excised from the phage according to the manufacturer's instructions. The plasmids obtained were reprobed to verify the positive results. DNA hybridizations were performed at $65^{\circ} \mathrm{C}$ as recommended in the Genus kit manual. The probe was prepared by PCR following the procedure of Lion \& Haas (1990), except $10 \times$ DIG DNA labelling mixture (Boehringer Mannheim) was substituted for the nucleotides. PCR was performed with an annealing temperature of $45^{\circ} \mathrm{C}$ on a DNA Thermal Cycler (Perkin Elmer Cetus) using Taq polymerase from either Perkin Elmer Cetus or Promega. The primers $\left(5^{\prime}\right.$-ATGTTAAAACGTAAAGCTCTACAA and 5'-CTGCAGACCAGACACGCTCAGTTC), which were based on the sequence data from Soto-Gil (1988), were used to amplify most of the coding region (see Fig. 1). The single PCR product was $1.7 \mathrm{~kb}$, the same length as predicted from the sequence information. Primers were synthesized by Genosys.

Colonies and plaques which hybridized to the probe were also screened for chitinase activity using a chitin analogue, 4methylumbelliferyl $\beta$-D- $N, N^{\prime}$-diacetylchitobioside (MUFdiNAG; Sigma), which fluoresces when hydrolysed. Activity in plaques or colonies on agar plates was detected by spraying or spotting $50 \mu \mathrm{M}$ MUF-diNAG $(5 \mathrm{mM}$ stock in $\mathrm{N}, \mathrm{N}$ dimethylformamide; Sigma) in $0.1 \mathrm{M}$ phosphate buffer, $\mathrm{pH} 7 \cdot 5$. The plates were incubated at $37^{\circ} \mathrm{C}$ for $10-30 \mathrm{~min}$ and then viewed under UV light. Phage in plaques exposed to this screening method are still able to infect $E$. coli and be amplified.

Sequencing of chiA. DNA sequencing was performed using a Taq DyeDeoxy Cycle Sequencing kit (Applied Biosystems). Nested deletions from pALS101 (see Results) were prepared in both directions using a Stratagene Exo/Mung bean kit. Sequencing reactions were then performed using primers for the vector. The plasmid pJM2 was used to obtain the missing C-terminal portion of $c h i A$. The first strand was sequenced by 'walking' (Giesecke et al., 1992) downstream from the end of chiA1 using primers synthesized by either Genosys or DNAgency. The second strand was then sequenced using primers synthesized from the first strand. The region of $c h i A$ between the end of pALS101 to the end of chiA1 was sequenced once to confirm the previous sequence data (Soto-Gil, 1988). Both strands from all other regions were sequenced.

Sequence analysis was performed using SeqEd (Applied Biosystems), GDE and GCG programs. Database searches were performed using FASTA from the European Bioinformatics Institute World Wide Web server. Default settings were used with the programs.

Construction of pChiA1 and pChiA2. A plasmid, pChiA1, encoding a protein containing both the putative catalytic and chitin-binding regions was prepared using genomic DNA from $V$. harveyi $\mathrm{BB} 7$. The DNA was amplified using the $c h i A 1$ primers mentioned above, made blunt-ended with Mung bean nuclease and ligated into blunt-ended, alkaline-phosphatasetreated pBluescript II $\mathrm{KS}(-)$. Another plasmid, pChiA2, was prepared by ligating the PstI-FspI fragment from pChiA1, containing most of the gene, into pBluescript II $\mathrm{KS}(-)$ digested with PstI and SmaI. After electroporating the ligation reactions into XL-1 Blue MRF' (Svitil et al., 1997), colonies were screened for chitinase activity with MUF-diNAG. 
To examine the chitinases produced by these clones in further detail, crude protein extracts were prepared from IPTGinduced cells as described before (Svitil et al., 1997). Briefly, sonicated cells were incubated with sarcosyl $(0 \cdot 1 \%, \mathrm{w} / \mathrm{v}$, final concentration) for $1 \mathrm{~h}$ on ice, then centrifuged to remove cell debris. These crude protein extracts were used to test whether or not the two versions of ChiA could specifically bind to chitin. The procedure was as previously described (Montgomery \& Kirchman, 1993). Protein extracts were also tested for the capacity to hydrolyse two types of chitin. Degradation of glycol chitin after SDS-PAGE was tested as previously described (Svitil et al., 1997). Degradation of colloidal chitin was examined by incubating cell extracts with various concentrations of chitin at $37^{\circ} \mathrm{C}$ for $4 \mathrm{~h}$, after which $3 \mathrm{M} \mathrm{HCl}$ was added. The mixture was then centrifuged to remove precipitated protein and undegraded chitin. The supernatant containing soluble by-products from the degraded chitin was hydrolysed at $95^{\circ} \mathrm{C}$ for $4 \mathrm{~h}$ in vacuum-sealed ampules. These conditions were effective in hydrolysing oligomers of $\mathrm{N}$ acetylglucosamine to glucosamine, which was measured by HPLC with pulse-amperometric detection (Borch \& Kirchman, 1997). To examine the by-products of hydrolysis by ChiA, the supernatant containing soluble by-products was analysed by HPLC without heat and acid hydrolysis. The HPLC method could separate glucosamine, $\mathrm{N}$-acetylglucosamine and the dimer of $\mathrm{N}$-acetylglucosamine ; the trimer and tetramer could be resolved from the other compounds, but they formed two overlapping peaks on the chromatogram. Samples were diluted 500- to 1000 -fold with deionized water before HPLC analysis. Fucose was used as an internal standard.

To examine the relative diffusion rate of the two forms of ChiA, protein extracts were added to wells in agarose plates with and without colloidal chitin. After $24 \mathrm{~h}$, melted agarose containing $10 \mu \mathrm{M}$ MUF-diNAG was poured over the plate, incubated for $1 \mathrm{~h}$, then observed with UV light to detect the presence of the enzyme, especially in the agarose plate without colloidal chitin. The diameter of the fluorescence area around the centre well was measured. In all degradation and diffusion experiments, equal amounts of protein extract of clones containing either ChiA1 or ChiA2 were used.

\section{RESULTS}

\section{Identification of chiA-containing clones}

Two genomic libraries were constructed from V. harveyi BB7 and screened to identify clones containing the gene for a major chitinase, chiA. To identify an intact chiA gene the libraries were probed with $c h i A 1$, which was made from a part of the coding region (map of $c h i A$ and surrounding regions in Fig. 1). In the plasmid library (550 colonies), the probe hybridized to a single clone (pPV1) with a $7 \mathrm{~kb}$ insert; this clone did not have chitinase activity. Using Southern blots, the region of pPV1 hybridized by chiA1 was identified and subcloned (pALS101; Fig. 1). Sequence data from the subclone and a restriction map of pPV1 revealed that only the $5^{\prime}$ terminal portion of $c h i A$ was present in pALS101 and pPV1. In the plaque library (4000 plaques), the chiA1 probe hybridized to at least six plaques, none of which had chitinase activity. Restriction mapping and partial sequencing identified clones containing the beginning (pJM1) or end (pJM2) of chiA, but none with the entire gene (Fig. 1). Attempts to construct a full-length chiA, by joining the cloned portions or amplification from primers, were unsuccessful, but the truncated portion originally obtained by Soto-Gil (1988) was successfully produced using PCR and was cloned (see below).

\section{Sequence analysis of chiA}

The complete sequence of chiA was obtained by sequencing the clones outlined in Fig. 1. The ORF of chiA encodes a 729 residue protein with a calculated molecular mass of $92 \mathrm{kDa}$. Analysis of the predicted amino acid sequence revealed characteristic features of a signal peptide which is required for membrane translocation (Inouye \& Halegoua, 1980; von Heijne, 1986). The putative site for cleavage of this signal peptide is after the twenty-fourth amino acid. The resulting peptide is calculated to be $89 \mathrm{kDa}$ which is close to the molecular mass of the excreted chitinase, $85 \mathrm{kDa}$ (SotoGil, 1988; Montgomery \& Kirchman, 1993). A clone (pChiA1; see below) with a portion of chiA produces a protein which is recognized by antibodies raised against the $85 \mathrm{kDa}$ excreted chitinase (Svitil et al., 1997). These data confirmed that the sequenced ORF does encode the excreted chitinase, ChiA.

The sequence contains the elements necessary for transcription. A promoter region is located upstream of the ORF. The initiation codon is preceded by a ribosome-binding site. Upstream of the ribosome-binding site is a region very similar to the $E$. coli consensus $-35 /-10$ sites, and the AT content is high $(81 \%)$ where strand-opening is predicted to occur, from the -10 region through the first three codons of the ORF.

\section{Comparison with other chitinases}

Catalytic domain. A search of the protein database by FASTA revealed several chitinases with portions similar to two regions in ChiA (Fig. 2). One section in the Nterminus appears to be the catalytic domain, based on its similarity $(24-29 \%)$ to the active portions in several plant, fungal and bacterial chitinases (Watanabe et al., 1993). For example, the V. harveyi ChiA is $29 \%$ similar to the catalytic domain of ChiD from $B$. circulans WL12 (Watanabe et al., 1992; ChiA residues 5-320) (Fig. 2). The catalytic site for chitinases contains four residues, two of which are essential for activity, and which are conserved among various prokaryotic, yeast and plant class III chitinases (Watanabe et al., 1993). ChiA of V. harveyi contains three of the four residues in this conserved region, amino acids 110-158 (Fig. 3). This conserved area is located in the region similar to $B$. circulans $\mathrm{ChiD}$. Additional residues appear conserved among the bacterial chitinases (Fig. 3), although overall these chitinases share little similarity. We determined a consensus catalytic domain consisting of 13 residues which are present in at least $69 \%$ of the sequences (Fig. 3).

Pairwise comparisons using BESTFIT revealed that the 

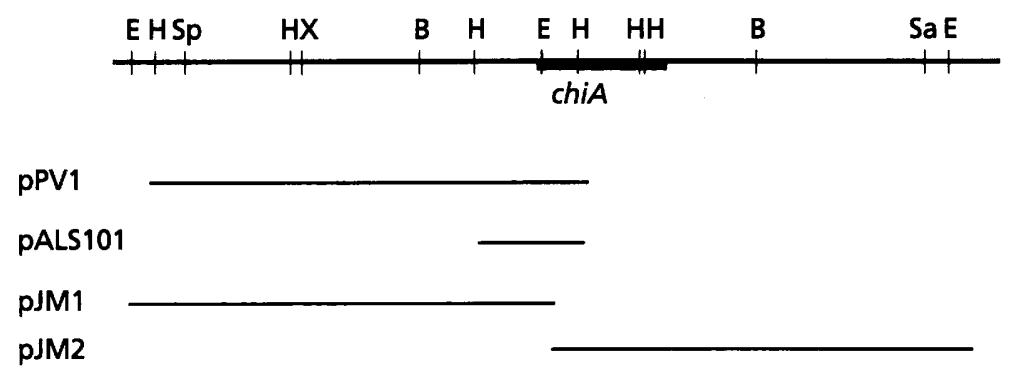

ChiA1

Total sequenced

$1 \mathrm{~kb}$

Fig. 1. Restriction map of chiA and surrounding DNA. Clone inserts and sequenced regions are given. $B, B a m H I ; E$, EcoRI; $\mathrm{H}$, HindlII (not all sites identified); $\mathrm{Sa}$, Sall; Sp, Spel; X, BstXI.

\begin{tabular}{|c|c|c|}
\hline $\begin{array}{l}\text { Catalytic } \\
\text { domain (120-160) }\end{array}$ & $\begin{array}{l}\text { Chitin-binding } \\
\text { domain }(511-550)\end{array}$ & \\
\hline \multirow[t]{8}{*}{ 曲 } & 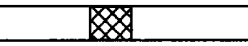 & ChiA (729 amino acids) \\
\hline & & ChiA1 (579 amino acids) \\
\hline & & ChiA2 (510 amino acids) \\
\hline & & Repeats in protein $(53 \%)$ \\
\hline & & B. circulans ChiD ( $29 \%)$ \\
\hline & & Alteromonas ChiA (29\%) \\
\hline & & B. circulans ChiA1 (21\%) \\
\hline & & $\begin{array}{l}\text { Similarity at nucleotide level } \\
\text { to Alteromonas chitinase } \\
\text { gene }(64 \%)\end{array}$ \\
\hline
\end{tabular}

Fig. 2. Schematic representation of regions identified in ChiA. The regions with similarities to chitinases from other bacteria are identified; the percentage identity is given in parentheses. catalytic domains can be divided into at least four groups (Fig. 3). Group I (93\% mean similarity) consists of 4 chitinases, all from $\gamma$-proteobacteria (Gram-negative). Members of Group II (85\% mean similarity) include a chitinase from a $\gamma$-proteobacterium and three chitinases from Gram-positive high-G + C-content bacteria. Group III ( $83 \%$ mean similarity) is comprised of five chitinases all from Gram-positive low-G + C-content bacteria. Group IV ( $71 \%$ mean similarity) contains three chitinases from vibrios (including ChiA from $V$. harveyi) and three chitinases from Gram-positive bacteria. The domains which could not be placed into a group were assigned to Group IV ( $51 \%$ mean similarity). Clearly, these comparisons indicate that the evolution of the catalytic domain does not follow bacterial phylogeny and that taxonomically related bacteria may have dissimilar catalytic domains. In fact, three chitinases from a single species (Aeromonas sp.) were not very similar (46\% mean similarity). In pairwise comparisons, there was no correlation $(r=0 \cdot 192 ; n=136)$ between percentage similarity of catalytic domains and of $16 \mathrm{~S}$ rRNA genes.

Chitin-binding domain. The second region in V. harveyi ChiA which is similar to other proteins as revealed by
FASTA appears to be the chitin-binding domain (Fig. 2). Watanabe et al. (1990) first identified a chitin-binding domain in ChiA1 from B. circulans and later found a similar domain in another B. circulans chitinase, ChiD, by sequence analysis (Watanabe et al., 1992). A search of $V$. harveyi ChiA revealed a region (amino acids 511-551) which is $37 \%$ and $26 \%$ identical to B. circulans ChiA1 (CA) and ChiD (ND) binding regions, respectively (Fig. 4). This region is also similar to the Alteromonas chitinase (Figs 2, 4), even at the nucleotide level, suggesting that it is conserved because of chitin-binding capacities. Searches using this proposed chitin-binding region revealed several chitinases containing this domain (Fig. 4). Because many residues are conserved in this domain, we were able to generate a consensus binding sequence, which consists of 15 residues (17 including conserved aromatic residues) conserved in at least $69 \%$ of the sequences (Fig. 4). The latter portion of this domain, which is absent from the $B$. circulans chitinases and present in only the Gram-negative bacteria, contains a conserved aromatic region with at least one tryptophan (corresponding to ChiA residues 537 and 538).

The chitin-binding domains cannot be classified into the same groups as defined by the catalytic domains, based 


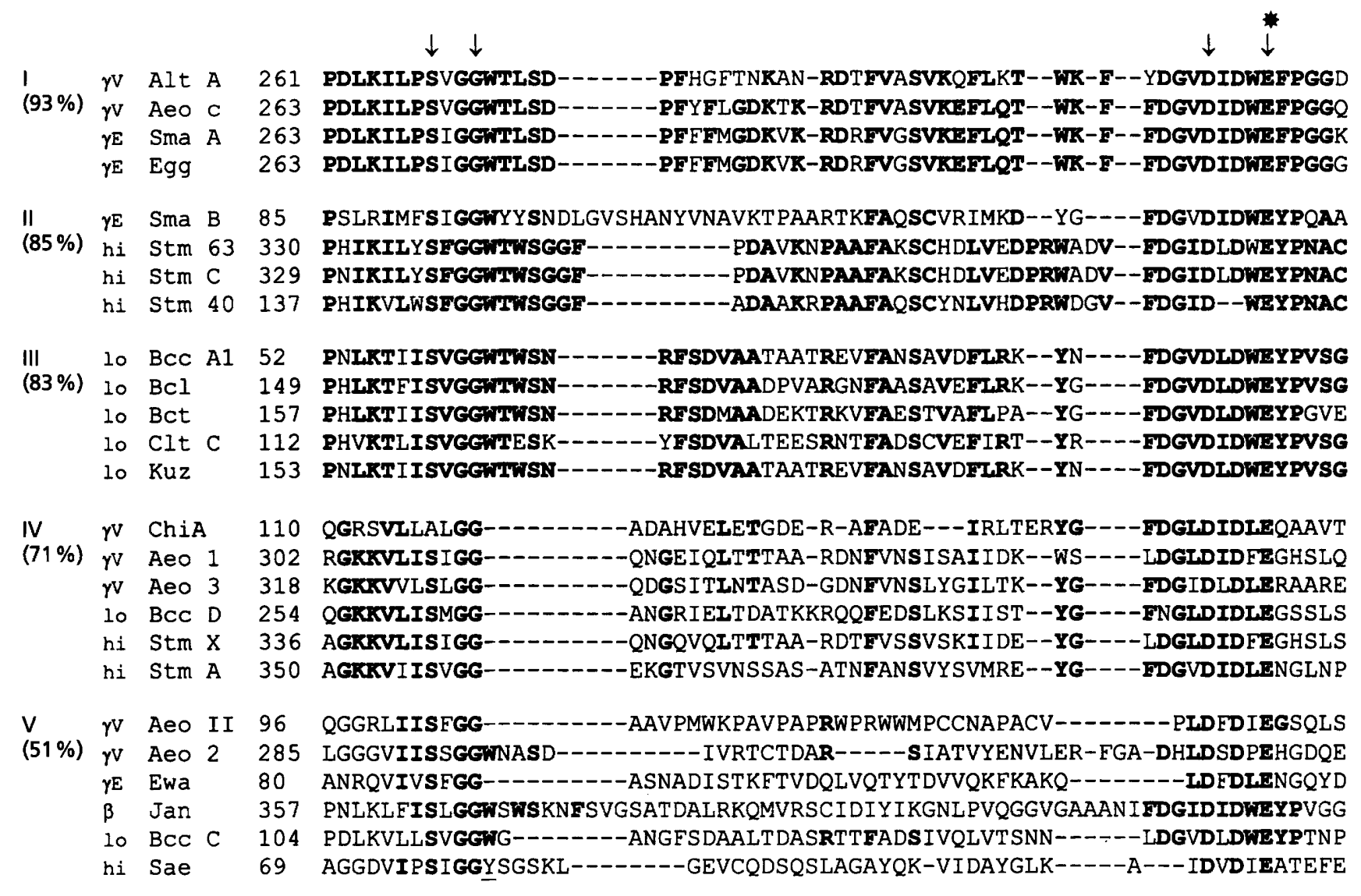

consensus

K S GG

$\mathbf{E} \quad \mathbf{S}$

C FDG D D E

\begin{abstract}
Fig. 3. Comparison of putative catalytic region in bacterial chitinases. Conserved residues are in bold. Arrows indicate the four residues identified by Watanabe et al. (1993) as being conserved among bacterial and plant class III chitinases; *, residue necessary for activity (Watanabe et al., 1993); @, conserved aromatic residue; $\gamma \mathrm{E}$, Gram-negative $\gamma$-subdivision, family Enterobacteriaceae; $\gamma \mathrm{V}$, Gram-negative $\gamma$-subdivision, family Vibrionaceae; $\beta$, Gram-negative $\beta$-subdivision; lo, Gram-positive low-G + C-content; hi, Gram-positive high-G+C-content; Alt A, Alteromonas sp. strain 0-7 chitinase (accession number D13762; Tsujibo et al., 1993b); Aeo C, Aeromonas caviae chitinase (U09139; Sitrit et al., 1995); Sma A, Serratia marcescens chitinase A (X03657; Jones et al., 1986); Egg, Enterobacter agglomerans chitinase (U59304; Chernin et al., 1997); Sma B, S. marcescens ChiB (X15208; Harpster \& Dunsmuir, 1989); Stm 63, Streptomyces plicatus chitinase 63 (M82804; Robbins et al., 1992); Stm C, Streptomyces lividans chitinase C (D12647; Fujii \& Miyashita, 1993); Stm 40, Streptomyces thermoviolaceus chitinase 40 (D14536; Tsujibo et al., 1993a); Bcc A1, Bacillus circulans WL-12 chitinase A1 (J05599; Watanabe et al., 1990); Bcl, Bacillus licheniformis TP chitinase (U71214); Bct, Bacillus thuringiensis chitinase (U89796); Clt A, Clostridium thermocellum ChiA (Z68924); Kuz, Kurthia zopfii chitinase (D63702); ChiA, Vibrio harveyi BB7 chitinase A (this study); Aeo 1 and 3, Aeromonas sp. NO. 10S-24 chitinases ORF 1 and 3, respectively (D63139, D63141; Shiro et al., 1996); BCC D, B. circulans WL-12 chitinase D (D90534; Watanabe et al., 1992); Stm X, Streptomyces olivaceoviridis exochitinase (X71080; Blaak et al., 1993); Stm A, St. lividans 66 ChiA (D13775; Miyashita \& Fujii, 1993); Aeo II, Aeromonas sp. NO. 10S-24 chitinase II (D31818; Ueda et al., 1994); Aeo 2, Aeromonas sp. NO. 10 -24 chitinases ORF 2 (D63140; Shiro et al., 1996); Ewa, Ewingella americana chitinase (X90562); Jan, Janthinobacterium lividum chitinase chitin-binding domain 2 (U07025; Gleave et al., 1995); Bcc C, B. circulans WL-12 ChiC (D89568; Alam et al., 1995); Sae, Saccharopolyspora (Streptomyces) erythraeus chitinase (P14529; Kamei et al., 1989).
\end{abstract}

on pairwise comparisons using BESTFIT. There is no correlation between percentage similarities in the catalytic and chitin-binding domains $(r=0.183 ; n=65)$ in pairwise comparisons. However, unlike the catalytic domain, chitin-binding domains in chitinases from a single organism can be similar. For example, the five chitinases from Aeromonas sp. all share high similarity (mean $88 \%$ ).

To verify that the putative chitin-binding domain is necessary for binding to chitin, two clones expressing modified functional versions of ChiA were produced (Fig. 5). The protein produced from the first plasmid, pChiA1, contains the proposed catalytic and chitinbinding domains, while the other plasmid, pChiA2, encodes a protein lacking the putative chitin-binding domain. Sequencing of the second plasmid (pChiA2) confirmed the $3^{\prime}$ end of the gene and the lack of the putative chitin-binding domain (Fig. 5). The chitinases encoded by the two plasmids hydrolyse glycol chitin after SDS-PAGE, with apparent sizes of 60 and $67 \mathrm{kDa}$ for ChiA2 and ChiA1, respectively (Fig. 6a). These sizes 


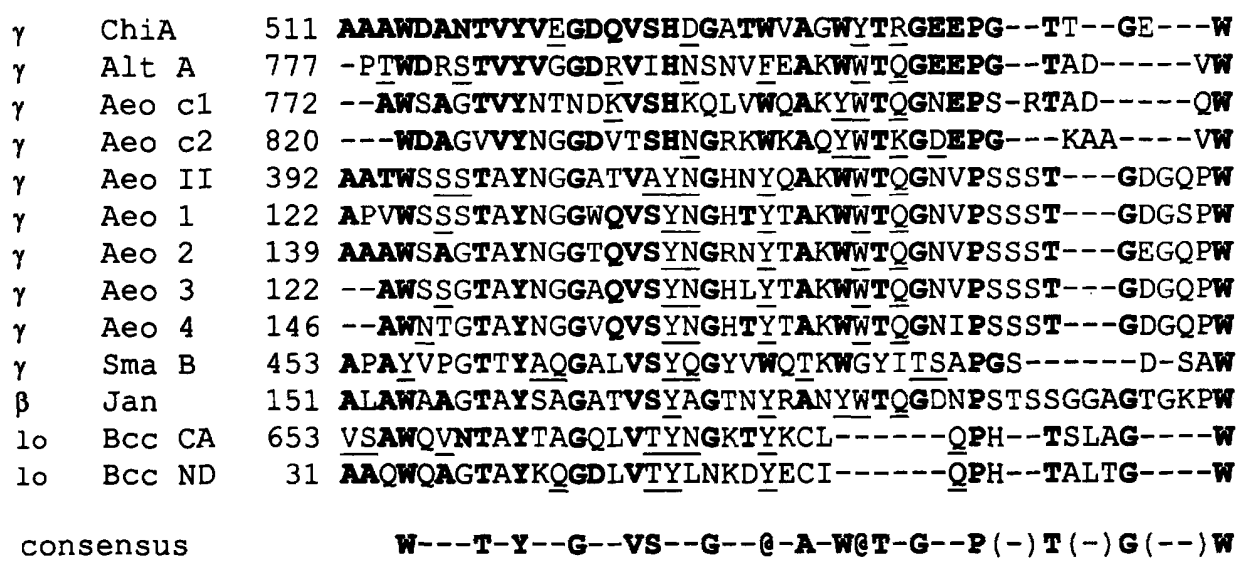

Fig. 4. Alignment of protein sequences to identify similarities in the putative bacterial chitin-binding domains. Conserved residues are in bold and closely related amino acids are underlined. Abbreviations and symbols are the same as in Fig. 3 , except that dashes indicate a variable number of intervening residues; Aeo $C 1$ and $C 2$, regions 1 and 2 in Aeromonas caviae chitinase (Sitrit et al., 1995); Aeo 4, Aeromonas sp. NO. 10S-24 ORF 4 (D63142; Shiro et al., 1996); Bcc CA, chitinbinding domain identified in Bacillus circulans WL-12 chitinase A1 (Watanabe et al., 1990); Bcc ND, chitin-binding domain identified in B. circulans WL-12 chitinase D (Watanabe et al., 1992).

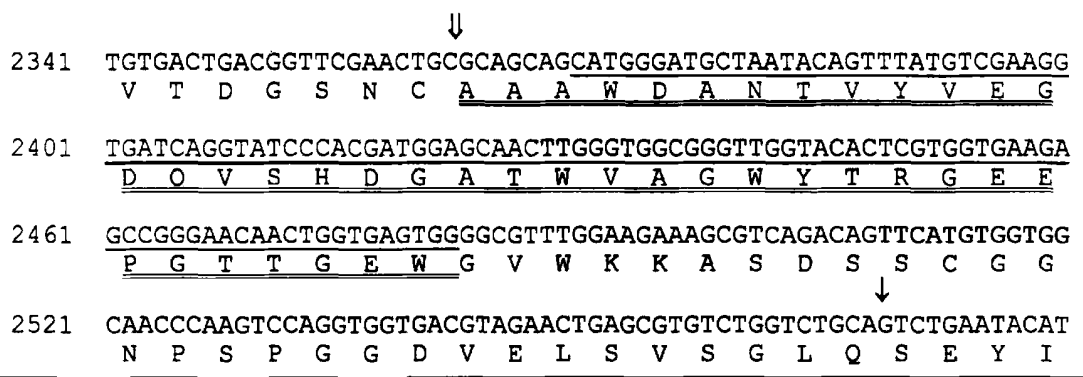

Fig. 5. Partial nucleotide sequence of chiA, showing the end of pChiA 1 and $P C h i A 2$. The numbering corresponds to that in the sequence reported to GenBank, accession number U81496. The deduced amino acid sequence is given below the nucleotide sequence. The end of pChiA1 $(\downarrow)$ and pChiA2 ( $\downarrow)$ are shown above the sequence. The nucleotide region similar to Alteromonas sp. strain 0-7 chitinase (64\%; Tsujibo et al., $1993 \mathrm{~b})$ is underlined once and the putative chitin-binding domain is underlined twice. are close to the size predicted for these clones, 62 and $70 \mathrm{kDa}$, respectively.

To test the role of the putative chitin-binding domain in mediating binding of ChiA to chitin, extracts of E. coli expressing either ChiA1 or ChiA2 were exposed to chitin and proteins binding to chitin were analysed by SDS-PAGE. Fig. 6(b) shows the binding of ChiA1 to chitin whereas ChiA2 does not appear to bind; proteins removed from chitin exposed to ChiA2-containing extracts (Fig. 6, lane 2) are nearly the same as those from $E$. coli bearing the vector without an insert, i.e. the negative control (Fig. 6, lane K). These data confirm the role of the chitin-binding domain in ChiA.

The role of the chitin-binding domain in chitin degradation was examined in greater detail in two series of experiments. In addition to hydrolysing glycol chitin, cell extracts containing ChiA2 degraded colloidal chitin as evident from clearing zones on colloidal chitin plates, but the zones were more opaque. Additional experiments confirmed that loss of the chitin-binding domain decreased the effectiveness of the enzyme. Cell extracts containing ChiA1 hydrolysed colloidal chitin about fivefold more effectively than ChiA2 extracts (Fig. 7). Preliminary HPLC analysis indicated that the major by- product of ChiA1 hydrolysis was the dimer of $\mathrm{N}$ acetylglucosamine $(80 \%)$, with much smaller amounts of the monomer $(10 \%)$ and larger oligomers $\langle 10 \%)$ also present. In contrast, $\mathrm{ChiA} 2$ appeared to release relatively more large oligomers (trimers and tetramers) than ChiA1, suggesting that removal of the chitin-binding domain increased relative endochitinase activity of ChiA.

Diffusion of the two forms of ChiA was examined with colloidal chitin plates. The diameter of the clearing zone produced by ChiA2 on colloidal chitin plates was $20 \%$ wider than that of the clearing zone produced by ChiA1. The extent of diffusion on agarose plates without colloidal chitin was the same for cell extracts containing either ChiA1 or ChiA2. These results suggest that the chitin-binding domain inhibited diffusion of ChiA1 in the presence of colloidal chitin.

\section{DISCUSSION}

Sequences of bacterial chitinases can differ greatly, except for possibly two regions, the catalytic domain and the chitin-binding domain. ChiA from the marine bacterium $V$. harveyi contains these two regions. Like 
(a)

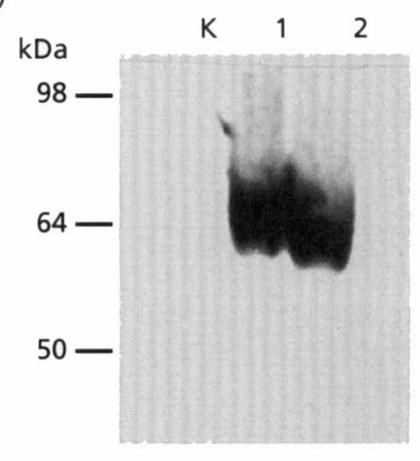

(b)

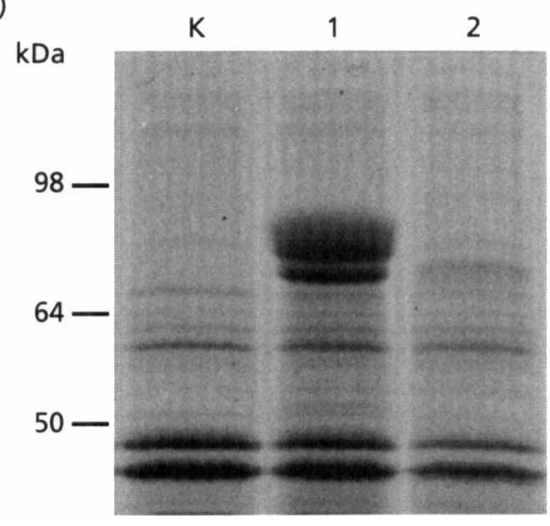

Fig. 6. Chitinase activity and chitin-binding capacity of truncated ChiA proteins. (a) Glycol chitin gel. Dark area indicates hydrolysis of chitin after SDS-PAGE. (b) SDS-PAGE of chitin-binding proteins. Protein extracts were added to chitin, then bound proteins were eluted and analysed by SDS-PAGE. Lanes: $\mathrm{K}$, vector alone [pBluescript II KS $(-)$ ]; 1, pChiA1; 2, pChiA2 (missing presumptive chitin-binding domain).

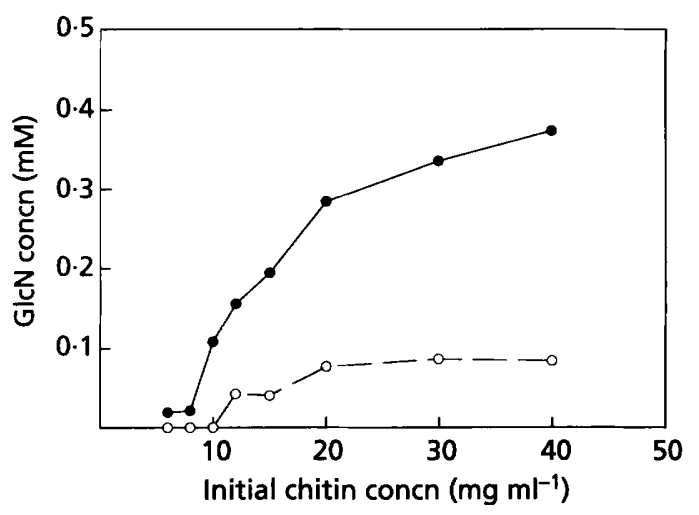

Fig. 7. Degradation of colloidal chitin by truncated ChiA proteins. Various concentrations of colloidal chitin were incubated for $4 \mathrm{~h}$ with extracts containing either ChiA1, with chitin-binding domain (O) or ChiA2, without chitin-binding domain (O). Hydrolysis by ChiA1 and ChiA2 was assessed by measuring glucosamine ( $\mathrm{GlCN}$ ) concentration after acid and heat hydrolysis of all soluble polymers. the arrangement of domains in $B$. circulans ChiA1 (Watanabe et al., 1993), ChiA from V. harveyi has its catalytic domain in the $\mathrm{N}$-terminal portion and chitinbinding domain near the C-terminus. Although both regions share similarity with analogous domains in other microbial chitinases, we found more conserved residues (present in at least $69 \%$ of the sequences) in the chitin-binding domain (17) than in the catalytic domain (13). The sequence analysis presented here suggests that, in addition to the demonstrated chitin-binding domains in $V$. harveyi ChiA and two B. circulans chitinases, binding domains are also present in chitinases from Alteromonas sp., Aeromonas sp., Janthinobacterium lividum and Serratia marcescens. Recently, Morimoto et al. (1997) found a similar binding domain in ChiB from C. paraputrificum.

Chitin-binding domains appear to increase hydrolysis of specific forms of chitin, as has been found for cellulases (Coutinho et al., 1993), but the binding domain may have other roles in chitin hydrolysis as well. Morimoto et al. (1997) found that removing the chitin-binding domain from C. paraputrificum $\mathrm{ChiB}$ reduced hydrolysis of unprocessed chitin but not of colloidal chitin. Apparently, the binding domain only impacts hydrolysis of the more tightly packed strands of unprocessed chitin. In contrast, we found that removing the chitin-binding domain from $V$. harveyi ChiA decreased hydrolysis of even colloidal chitin. However, V. harveyi ChiA does not appear to be the same type of chitinase as it produces more large oligomers (trimers and tetramers) of $N$ acetylglucosamine than reported by Morimoto et al. (1997) for C. paraputrificum ChiB. Even so, we found that removing the binding domain increased relative endochitinase activity of ChiA, suggesting that the chitin-binding domain affects how the enzyme accesses glycosidic bonds within the chitin strands, analogous to what Morimoto et al. (1997) observed.

Diffusion of chitinases in an organic matrix containing chitin may be affected by the chitin-binding domain, although this seems to vary with the chitinase. We observed that diffusion of $V$. harveyi ChiA in agarose with colloidal chitin was inhibited by the chitin-binding domain. In contrast, Watanabe et al. (1994) did not observe any difference in clearing zone size produced by a $B$. circulans chitinase with and without its chitinbinding domain, suggesting that the domain had no effect on diffusion of the enzyme. The original habitats of the two bacteria may explain the different results. Unlike the aqueous environment of $V$. harveyi, $B$. circulans was originally isolated from soil (Tanaka $\&$ Phaff, 1965) where diffusion is restricted. Chitinases of aquatic bacteria like $V$. harveyi may be selected to bind more tightly to chitin and thus diffuse more slowly in organic detritus suspended in aquatic habitats compared with chitinases selected for in soil environments.

The chitin-binding domain of bacterial chitinases is unlike the domain found in plant chitinases, which contains eight conserved cysteine residues. In contrast, several aromatic amino acids, principally tryptophan, are prominent among the residues conserved in the 


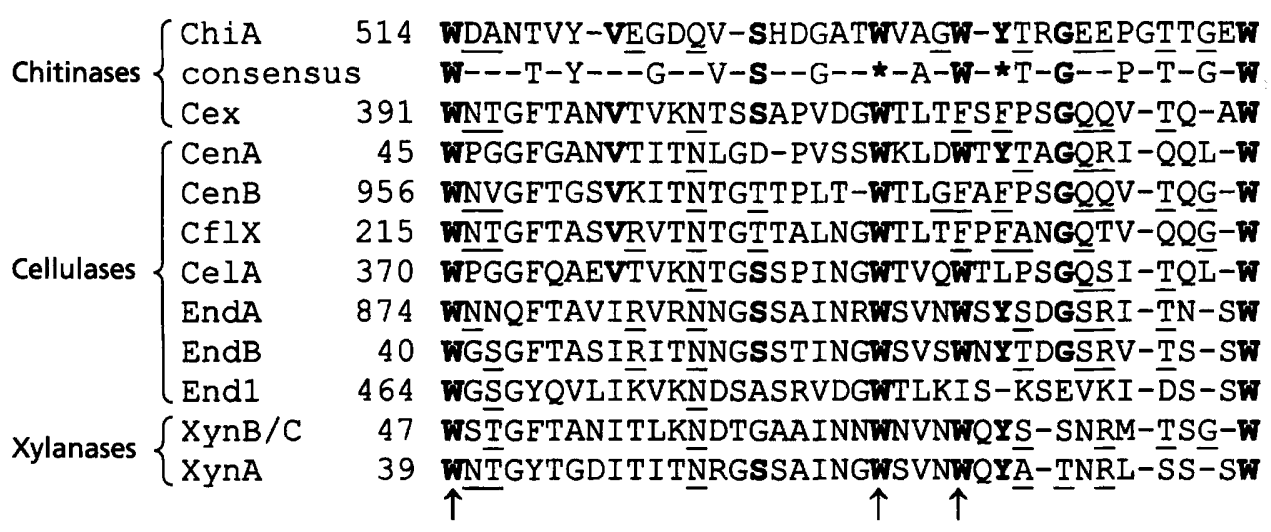

Fig. 8. Comparison of ChiA and consensus chitin-binding domain with bacterial cellulose- and xylan-binding domains. The bacterial cellulose-binding domain alignment is from Gilkes et al. (1991). Residues conserved or closely related to amino acids in the ChiA binding domain are in bold or underlined, respectively. The arrows indicate the tryptophan residues shown to be essential for cellulose binding in XynA (Poole et al., 1993). ChiA, Vibrio harveyi chitinase A (this study); consensus, chitin-binding consensus sequence, see Fig. 5; Cex, Cellulomonas fimi exoglucanase (O'Neill et al., 1986); CenA, C. fimi endoglucanase A (Wong et al., 1986); CenB, C. fimi endoglucanase B (Meinke et al., 1991a); CflX, Cellulomonas flavigena ORF X (Al-Tawheed, 1988); CelA, Microbispora bispora endoglucanase A (Yablonsky et al., 1988); EndA, Pseudomonas fluorescens subsp. cellulosa endoglucanase A (Hall \& Gilbert, 1988); EndB, $P$. fluorescens subsp. cellulosa endoglucanase B (Gilbert et al., 1990); End1, Butyrivibrio fibrisolvens endoglucanase 1 (Berger et al., 1990); $\mathrm{XynB} / C, P$. fluorescens subsp. cellulosa xylanases B and $C$ (Kellett et al., 1990); XynA, $P$. fluorescens subsp. cellulosa xylanase A (Hall et al., 1989).

bacterial chitin-binding domain. Tryptophans have been shown to be involved in the binding of a cellulase to cellulose (Poole et al., 1993) and have been implicated in the binding of a non-catalytic chitin-binding protein to chitin (Schnellmann et al., 1994). Some of the Gramnegative bacteria have another aromatic amino acid (phenylalanine or tyrosine) in place of the second or third tryptophan in the chitin-binding domain. Aromatic amino acids appear to be essential for hydrophobic binding of $1,4-\beta$-glycanases to polysaccharides (Poole $e t$ al., 1993).

Fig. 8 illustrates the similarities between the consensus microbial chitin-binding domain and the carbohydratebinding domains for cellulose and another 1,4- $\beta$-glycan, xylan. In addition to conserved tryptophans, several other residues (or conserved replacements) appear in both domains (Fig. 8). The role of these other residues in the binding of $1,4-\beta$-glycanases to their respective substrates is not known. Regardless, the similarity between the two carbohydrate-binding domains suggests that these 1,4- $\beta$-glycanases bind to carbohydrates by a similar mechanism. In further support of this hypothesis, it is worthwhile noting that some cellulosebinding domains can bind to chitin (Warren, 1996) and a chitinase has been shown to bind to cellulose (Morimoto et al., 1997).

ChiA from $V$. harveyi does not have all the domains found in other chitinases. Unlike the chitinases in $B$. circulans (Watanabe et al., 1990,1992) and Streptomyces olivaceoviridis (Blaak et al., 1993), ChiA from V. harveyi does not have a fibronectin type III domain, which occurs in a number of prokaryotic extracellular enzymes (including cellulases) that degrade insoluble polymers (Meinke et al., 1991b; Bork \& Doolittle, 1992). However, the $V$. harveyi ChiA may have another region that serves the same purpose. In the $\mathrm{N}$-terminal region of the chitin-binding domain, ChiA from $V$. harveyi contains a pair of repeats which are 68 residues long and $53 \%$ identical (Fig. 2). These repeats were found to be cadherin-like domains by Morimoto et al. (1997). Cadherins are animal cell proteins involved in calciumdependent cell adhesion (Takeichi et al., 1988). As Watanabe et al. (1994) hypothesized for the fibronectin type III repeats, the repeats in ChiA may help maintain the optimal distance and orientation between catalytic and chitin-binding domains.

This study adds to other evidence indicating that $1,4-\beta$ glycanases arose by mutation and domain shuffling (Gilkes et al., 1991) and that the catalytic and carbohydrate-binding domains of bacterial 1,4- $\beta$-glycanases have evolved separately. As in cellulases (Gilkes et al., 1991), the catalytic domains of chitinases from phylogenetically diverse bacteria share some similarity and can be divided into groups independent of phylogeny. Variation in chitin-binding domains also does not appear to follow phylogeny, although the binding domains of chitinases from a single bacterium can be quite similar, unlike the catalytic domains, again analogous to cellulases (Gilkes et al., 1991). Although further work is needed, our results suggest that chitin-binding domains have evolved not only to aid in hydrolysis of different forms of chitin but also in response to factors that affect movement of the enzyme along the substrate and in different environments. 


\section{ACKNOWLEDGEMENTS}

This work was supported by ONR grant N00014-93-1-0458. We wish to thank Philippe Vandevivere for construction and preliminary screening of the plasmid library, Dawn Gupta for helping screen the phage library and John McDonald for his assistance in sequencing chiA.

\section{REFERENCES}

Alam, M., Nikaidou, N., Tanaka, H. \& Watanabe, T. (1995). Cloning and sequencing of chiC gene of Bacillus circulans WL-12 and relationship of its product to some other chitinases and chitinase-like proteins. J Ferment Bioeng 80, 454-461.

Al-Tawheed, A. R. (1988). Molecular characterization of cellulase genes from Cellulomonas flavigena. MSc thesis. University of Dublin Trinity College.

Béguin, P. (1990). Molecular biology of cellulose degradation. Annu Rev Microbiol 44, 219-248.

Berger, E., Jones, W. A., Jones, D. T. \& Woods, D. R. (1990). Sequencing and expression of a cellodextrinase (ced1) gene from Butyrivibrio fibrosolvens $\mathrm{H} 17 \mathrm{c}$ cloned in Escherichia coli. Mol Gen Genet 223, 310-318.

Blaak, H., Schnellmann, J., Walter, S., Henrissat, B. \& Schrempf, H. (1993). Characteristics of an exochitinase from Streptomyces olivaceoviridis, its corresponding gene, putative protein domains and relationship to other chitinases. Eur J Biochem 214, 659-669.

Borch, N. H. \& Kirchman, D. L. (1997). Concentration and composition of dissolved combined neutral sugars (polysaccharides) in seawater determined by HPLC-PAD. Mar Chem 57, 85-95.

Bork, P. \& Doolittle, R. (1992). Proposed acquisition of an animal protein domain by bacteria. Proc Natl Acad Sci USA 89, 8990-8994.

Chernin, L. S., de la Fuente, L., Sobolev, V., Haran, S., Vorgias, C. E., Oppenheim, A. B. \& Chet, I. (1997). Molecular cloning, structural analysis, and expression in Escherichia coli of a chitinase gene from Enterobacter agglomerans. Appl Environ Microbiol 63, 834-839.

Coutinho, J. B., Gilkes, N. R., Kilburn, D. G., Warren, R. A. J. \& Miller, R. C., Jr (1993). The nature of the cellulose-binding domain affects the activities of a bacterial endoglucanase on different forms of cellulose. FEMS Microbiol Lett 113, 211-218.

Fujii, T. \& Miyashita, K. (1993). Multiple domain structure in a chitinase gene (chiC) of Streptomyces lividans. J Gen Microbiol $139,677-686$.

Giesecke, H., Obermaier, B., Domdey, H. \& Neubert, W. J. (1992). Rapid sequencing of the sendai virus $6.8 \mathrm{~kb}$ large (L.) gene through primer walking with an automated DNA sequencer. $J$ Virol Methods 38, 47-60.

Gilbert, H. J., Hall, J., Hazlewood, G. P. \& Ferreira, L. M. A. (1990). The N-terminal region of an endoglucanase from Pseudomonas fluorescens subspecies cellulosa constitutes a cellulose-binding domain that is distinct from the catalytic centre. Mol Microbiol 4, 759-767.

Gilkes, N. R., Henrissat, B., Kilburn, D. G., Miller, R. C., Jr \& Warren, R. A. J. (1991). Domains in microbial $\beta$-1,4-glycanases: sequence conservation, function, and enzyme families. Microbial $\operatorname{Rev~55,~303-315.~}$

Gleave, A. P., Taylor, R. K., Morris, B. A. \& Greenwood, D. R. (1995). Cloning and sequencing of a gene encoding the $69-\mathrm{kDa}$ extracellular chitinase of Janthinobacterium lividum. FEMS Microbiol Lett 131, 279-288.
Gooday, G. W. (1990). The ecology of chitin degradation. Adv Microb Ecol 11, 387-430.

Graham, L. S. \& Sticklen, M. S. (1994). Plant chitinases. Can J Bot 72, 1057-1083.

Hall, J. \& Gilbert, H. J. (1988). The nucleotide sequence of a carboxymethylcellulase gene from Pseudomonas fluorescens subsp. cellulosa. Mol Gen Genet 213, 112-117.

Hall, J., Hazlewood, G. P., Huskisson, N. S., Durrant, A. J. \& Gilbert, H. J. (1989). Conserved serine-rich sequences in xylanase and cellulase from Pseudomonas fluorescens subspecies cellulosa: internal signal sequence and unusual protein processing. $\mathrm{Mol}$ Microbiol 3, 1211-1219.

Harpster, M. H. \& Dunsmuir, P. (1989). Nucleotide sequence of the chitinase B gene of Serratia marcescens. Nucleic Acids Res 17, 5395.

von Heijne, G. (1986). A new method for predicting signal sequence cleavage sites. Nucleic Acids Res 14, 4683-4690.

Inouye, M. \& Halegoua, S. (1980). Secretion and membrane localization of proteins in E. coli. Crit Rev Biochem Mol Biol 7, 339-371.

Jannatipour, M., Soto-Gil, R. W., Childers, L. C. \& Zyskind, J. W. (1987). Translocation of Vibrio harveyi $\mathrm{N}, \mathrm{N}^{\prime}$-diacetylchitobiase to the outer membrane of Escherichia coli. J Bacteriol 169, $3785-3791$.

Jones, J. D. G., Grady, K. L., Suslow, T. V. \& Bedbrook, J. R. (1986). Isolation and characterization of genes encoding two chitinase enzymes from Serratia marcescens. EMBO J 5, 467-473.

Kamei, K., Yamamura, Y., Hara, S. \& Ikenaka, T. (1989). Amino acid sequence of chitinase from Streptomyces erythraeus. J Biochem 105, 979-985.

Kellett, L. E., Poole, D. M., Ferreira, M. A., Durrant, A. J., Hazlewood, G. P. \& Gilbert, H. J. (1990). Xylanase B and an arabinofuranosidase from Pseudomonas fluorescens subsp. cellulosa contain identical cellulose-binding domains and are encoded by adjacent genes. Biochem J 272, 369-376.

Lion, T. \& Haas, O. A. (1990). Nonradioactive labeling of probe with digoxigenin by polymerase chain reaction. Anal Biochem 188, 335-337.

Meinke, A., Braun, C., Gilkes, N. R., Kilburn, D. G., Miller, R. C., Jr \& Warren, R. A. J. (1991a). Unusual sequence organization in CenB, an inverting endoglucanase from Cellulomonas fimi. J Bacteriol 171, 308-314.

Meinke, A., Gilkes, N. R., Kilburn, D. G., Miller, R. C., Jr \& Warren, R. A. J. (1991b). Multiple domains in Endoglucanase B (CenC) from Cellulomonas fimi: functions and relatedness to domains in other polypeptides. J Bacteriol 173, 7126-7135.

Miyashita, K. \& Fujii, T. (1993). Nucleotide sequence and analysis of a gene (chiA) for a chitinase from Streptomyces lividans 66. Biosci Biotechnol Biochem 57, 1691-1698.

Montgomery, M. T. \& Kirchman, D. L. (1993). Role of chitinbinding proteins in the specific attachment of the marine bacterium Vibrio harveyi to chitin. Appl Environ Microbiol 59, 373-379.

Morimoto, K., Karita, S., Kimura, T., Sakka, K. \& Ohmiya, K. (1997). Cloning, sequencing, and expression of the gene encoding Clostridium paraputrificum chitinase $\mathrm{ChiB}$ and analysis of the functions of novel cadherin-like domains and a chitin-binding domain. J Bacteriol 179, 7306-7314.

O'Neill, G. P., Goh, S. H., Warren, R. A. J., Kilburn, D. G. \& Miller, R. C., Jr (1986). Structure of the gene encoding the exoglucanase of Cellulomonas fimi. Gene 44, 325-330. 
Poole, D. M., Hazelwood, G. P., Huskisson, N. S., Virden, R. \& Gilbert, H. J. (1993). The role of conserved tryptophan residues in the interaction of a bacterial cellulose binding domain with its ligand. FEMS Microbiol Lett 106, 77-84.

Robbins, P. W., Overbye, K., Albright, C. F., Benfield, B. \& Pero, J. (1992). Cloning and high level expression of chitinase encoding gene of Streptomyces plicatus. Gene 111, 69-76.

Schnellmann, J., Zeltins, A., Blaak, H. \& Schrempf, H. (1994). The novel lectin-like protein CHB1 is encoded by a chitin-inducible Streptomyces olivaceoviridis gene and binds specifically to crystalline $\alpha$-chitin of fungi and other organisms. Mol Microbiol $13,807-819$.

Shiro, M., Ueda, M., Kawaguchi, T. \& Arai, M. (1996). Cloning of a cluster of chitinase genes from Aeromonas sp. NO. 10S-24. Biochim Biophys Acta 1305, 44-48.

Sitrit, Y., Vorgias, C. E., Chet, I. \& Oppenheim, A. B. (1995). Cloning and primary structure of the chiA gene from Aeromonas caviae. J Bacteriol 177, 4187-4189.

Soto-Gil, R.W. (1988). Chitobiase and chitinase from Vibrio harveyi. PhD dissertation, University of California, San Diego and San Diego State University.

Svitil, A. L., N( Chadhain, S. M., Moore, J. A. \& Kirchman, D. L. (1997). Chitin degradation proteins produced by the marine bacterium Vibrio harveyi growing on different forms of chitin. Appl Environ Microbiol 63, 408-413.

Takeichi, M., Hatta, K., Nose, A. \& Nagafuchi, A. (1988). Identification of a gene family of cadherin cell adhesion molecules. Cell Differ Dev 25, 91-94.

Tanaka, H. \& Phaff, H. J. (1965). Enzymatic hydrolysis of yeast cell walls. I. Isolation of wall-decomposing organisms and separation and purification of lytic enzymes. J Bacteriol 89, 1570-1580.

Tsujibo, H., Endo, H., Minoura, K., Miyamoto, K. \& Inamori, Y. (1993a). Cloning and sequence analysis of the gene encoding a thermostable chitinase from Streptomyces thermoviolaceus OPC520. Gene 134, 113-117.

Tsujibo, H., Orikoshi, H., Tanno, H., Fujimoto, K., Miyamoto, K.,
Imada, C., Okami, Y. \& Inamori, Y. (1993b). Cloning, sequence, and expression of a chitinase gene from a marine bacterium, Alteromonas sp. strain 0-7. J Bacteriol 175, 176-181.

Ueda, M., Kawaguchi, T. \& Arai, M. (1994). Molecular cloning and nucleotide sequence of the gene encoding chitinase II from Aeromonas sp. NO. 10S-24. J Ferment Bioeng 78, 205-211.

Warren, R. A. J. (1996). Microbial hydrolysis of polysaccharides. Annu Rev Microbiol 50, 183-212.

Watanabe, T., Suzuki, K., Oyanagi, W., Ohnishi, K. \& Tanaka, H. (1990). Gene cloning of chitinase A1 from Bacillus circulans WL12 revealed its evolutionary relationship to Serratia chitinase and to the type III homology units of fibronectin. J Biol Chem 265, 15659-15665.

Watanabe, T., Oyanagi, W., Suzuki, K., Ohnishi, K. \& Tanaka, H. (1992). Structure of the gene encoding chitinase D of Bacillus circulans WL-12 and possible homology of the enzyme to other prokaryotic chitinases and class III plant chitinases. J Bacteriol $174,408-414$.

Watanabe, T., Kobori, K., Miyashita, K., Fujii, T., Sakai, H., Uchida, M. \& Tanaka, H. (1993). Identification of glutamic acid 104 and aspartic acid 200 in chitinase A1 of Bacillus circulans WL-12 as essential residues for chitinase activity. $J$ Biol Chem 268 , 18567-18572.

Watanabe, T., Ito, Y., Yamada, T., Hashimoto, M., Sekine, S. \& Tanaka, H. (1994). The roles of the C-terminal domain and type III domains of chitinase A1 from Bacillus circulans WL-12 in chitin degradation. J Bacteriol 176, 4465-4472.

Wong, W. K. R., Gerhard, B., Guo, Z. M., Kilburn, D. G., Warren, R. A. J. \& Miller, R. C., Jr (1986). Characterization and structure of an endoglucanase gene cenA of Cellulomonas fimi. Gene 44, 315-324.

Yablonsky, M. D., Bartley, T., Elliston, K. O., Kahrs, S. K., Shalita, Z. P. \& Eveleigh, D. E. (1988). Characterization and cloning of the cellulase complex of Microbispora bispora. FEMS Symp 43, 249-266.

Received 9 July 1997; revised 19 January 1998; accepted 22 January 1998. 